\title{
Optimal Diagnostic Approaches for Patients with Suspected Small Bowel Disease
}

\author{
Jae Hyun Kim and Won Moon \\ Department of Internal Medicine, Kosin University College of Medicine, Busan, Korea
}

While the domain of gastrointestinal endoscopy has made great strides over the last several decades, endoscopic assessment of the small bowel continues to be challenging. Recently, with the development of new technology including video capsule endoscopy, deviceassisted enteroscopy, and computed tomography/magnetic resonance enterography, a more thorough investigation of the small bowel is possible. In this article, we review the systematic approach for patients with suspected small bowel disease based on these advanced endoscopic and imaging systems. Clin Endosc 2016;49:364-369

Key Words: Small bowel; Hemorrhage; Inflammation; Neoplasms

\section{INTRODUCTION}

Small bowel disease is inherently difficult to diagnose as the small bowel is the longest section of the gastrointestinal tract (approximately 3 to $6 \mathrm{~m}$ in length) and is twisted between the stomach and the colon. However, recent advances in endoscopic and imaging systems have enabled systematic investigation of small bowel diseases such as unexplained gastrointestinal bleeding, inflammatory bowel disease, and small bowel tumors and obstruction. These advances have further helped to significantly reduce the use of invasive surgical approaches, which have traditionally been considered the standard approach. In this review, we discuss a systematic approach for patients with suspected small bowel disease based on these advanced endoscopic and imaging systems.

Received: May 11, 2016 Accepted: June 2, 2016

Correspondence: Won Moon

Division of Gastroenterology, Department of Internal Medicine, Kosin University College of Medicine, 262 Gamcheon-ro, Seo-gu, Busan 49267, Korea Tel: +82-51-990-5061, Fax: +82-51-990-5055, E-mail: moonone70@hanmail.net

(c) This is an Open Access article distributed under the terms of the Creative Commons Attribution Non-Commercial License (http://creativecommons.org/ licenses/by-nc/3.0) which permits unrestricted non-commercial use, distribution, and reproduction in any medium, provided the original work is properly cited.

\section{OBSCURE GASTROINTESTINAL BLEEDING}

Obscure gastrointestinal bleeding (OGIB) is defined as overt or occult bleeding of unknown origin that persists or recurs after initial upper endoscopic and colonoscopic examinations, as well as after imaging work-up for the small bowel. ${ }^{1}$ This type of bleeding accounts for approximately $5 \%$ of all cases of gastrointestinal bleeding and generally occurs in the small bowel. ${ }^{2}$ Overt OGIB refers to visible bleeding that can manifest as hematemesis, melena, or hematochezia; whereas occult OGIB refers to a positive fecal occult blood test result that may or may not be associated with iron deficiency anemia in the absence of any evidence of visible blood loss. ${ }^{3}$ In the past, it has been difficult to assess OGIB using diagnostic and therapeutic approaches and in certain cases, surgery or intraoperative enteroscopy have been required. Recently, the development of video capsule endoscopy (VCE) and device-assisted enteroscopy (DAE) has made detailed observation of the mucosa of the small bowel possible. Moreover, the introduction of computed tomography (CT) and magnetic resonance (MR) enterography has helped improve the accuracy of OGIB diagnosis. $^{1,4}$

The first approach for OGIB is to perform a second-look upper endoscopy and colonoscopy, with or without push 
enteroscopy. When studies of initial upper endoscopic and colonoscopic examinations are performed, certain factors (such as intermittent lesion bleeding, impaired visibility due to insufficient bowel preparation, lack of examiner skill and/or experience, and delayed examination after initial symptoms) can hinder the identification of lesions. ${ }^{2,3,5,6}$ In previous studies, the diagnostic rates of second-look endoscopy and colonoscopy have ranged from $3.5 \%$ to $25 \% .{ }^{4.7}$ If the results of the second-look investigations are normal, the next step is typically an assessment for small bowel. VCE is recommended as a first-line investigation for small bowel bleeding, as this technique allows for noninvasive assessment of the entire small bowel in $79 \%$ to $90 \%$ of all patients. ${ }^{4}$ The European Society of Gastrointestinal Endoscopy guidelines currently recommend that VCE could be performed as soon as possible after the first bleeding episode in patients with overt OGIB, ideally within 14 days. ${ }^{1}$ Recent studies have reported a VCE diagnostic rate of $60 \%$ to $83 \%$, a VCE positive predictive value of $94 \%$ to $97 \%$, and a VCE negative predictive value of $83 \%$ to $100 \% .{ }^{89}$ Situations where VCE findings lead to endoscopic or surgical intervention or a change in medical management have previously been reported in $37 \%$ to $87 \%$ of patients. ${ }^{10,11}$ In addition, one study found that $50 \%$ to $66 \%$ of all patients who underwent VCE-directed interventions remained free from recurrent bleeding at follow-up. ${ }^{12}$ In patients with positive VCE findings, it is helpful to decide on the approach (oral vs. anal) prior to performing DAE. VCE is very well tolerated by patients, with the primary complication of capsule retention occurring in only $1.4 \%$ to $3 \%$ of patients. One meta-analysis found that the diagnostic yield of VCE was comparable to that of DAE for small bowel diseases, including OGIB. ${ }^{13}$ While VCE does have some limitations, such as a lack of therapeutic capability and challenges in localizing the lesion, ${ }^{4}$ this technique has been proposed as the first-line approach for the evaluation of small bowel bleeding.

Techmetium-99m $\left({ }^{99 \mathrm{~m}} \mathrm{Tc}\right)$-labeled red blood cell scans are useful for assessing recurrent overt bleeding. Moreover, Meckel scans using ${ }^{99 \mathrm{~m}} \mathrm{TC}$-pertechnetate are informative for evaluating Meckel's diverticulum in young patients with OGIB., ${ }^{5,14}$ Angiography is useful for detecting and treating active bleeding foci and vascular lesions; however, this technique can only accurately diagnose the bleeding focus when the bleeding rate exceeds $0.5 \mathrm{~mL} / \mathrm{min} .{ }^{15}$ A meta-analysis of 18 studies found that the diagnostic yield of CT enterography was $40 \%$, whereas that of VCE was $53 \%{ }^{16} \mathrm{~A}$ further two studies $(n=63)$ have previously reported a diagnostic rate of CT enterography of $38 \%$, compared with $78 \%$ for double-balloon enteroscopy. ${ }^{1718}$ Moreover, three previous studies $(n=49)$ found a diagnostic

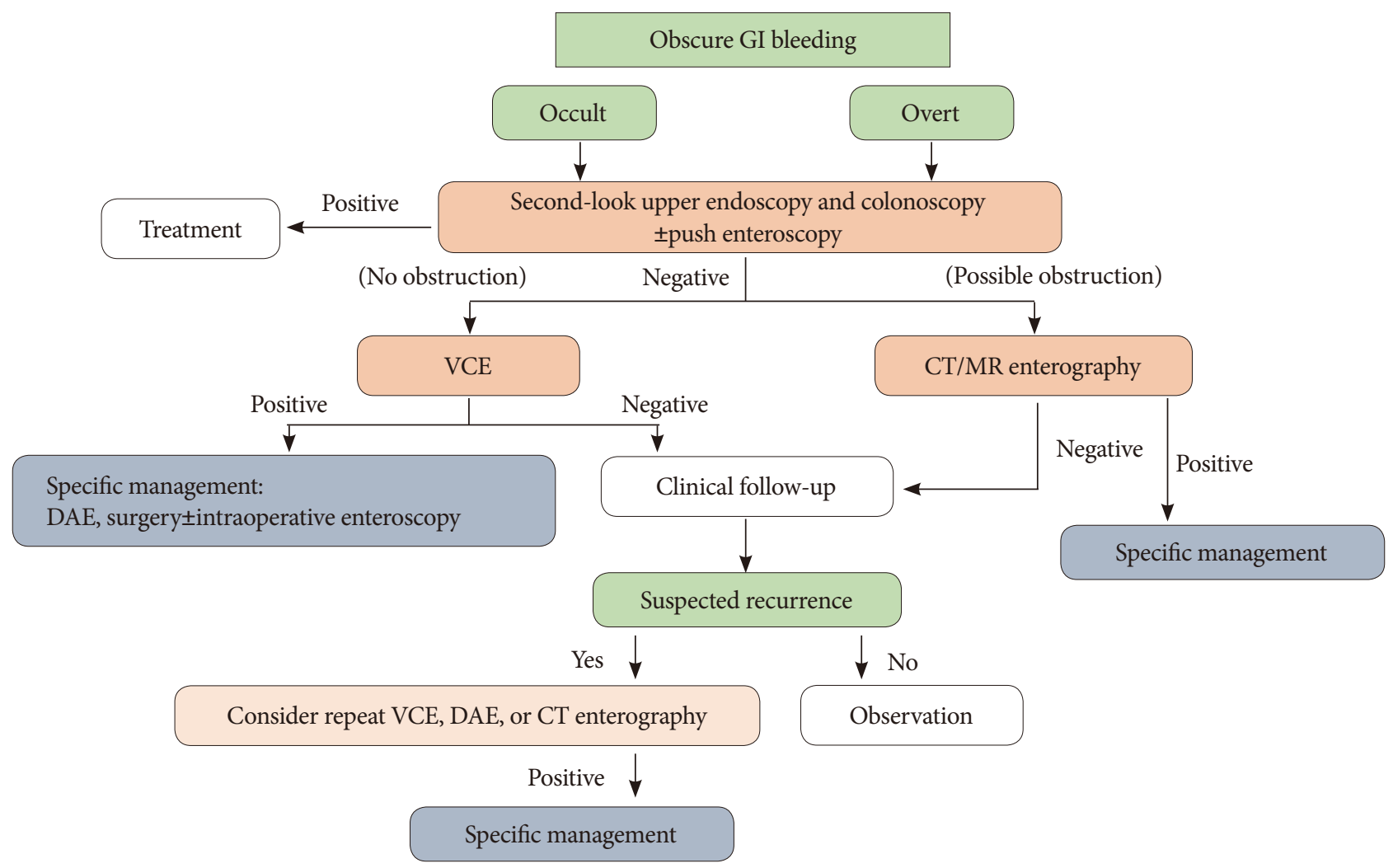

Fig. 1. Algorithm for obscure gastrointestinal bleeding. GI, gastrointestinal; VCE, video capsule endoscopy; CT, computed tomography; MR, magnetic resonance; DAE, device-assisted enteroscopy. 
yield of CT enterography of $64 \%$, compared with $60 \%$ for angiography. ${ }^{19-21}$ Therefore, CT enterography and VCE are considered complementary examinations to be performed prior to DAE for patients with OGIB.

The algorithm used for OGIB is presented in Fig. 1. VCE should always be considered for patients with occult or overt OGIB and based on VCE findings, DAE and surgical approaches may then be considered. However, in patients with strictures or obstructions, CT or MR enterography should be considered as the first-line approach. Patients with active overt bleeding require different management dependent on their hemodynamic state. In hemodynamically unstable patients with acute massive gastrointestinal bleeding, angiography should be considered emergently. Conversely, in hemodynamically stable patients with evidence of current bleeding, VCE and/or DAE are recommended. Intraoperative enteroscopy is an option during uncontrolled severe bleeding or in cases where the bleeding focus cannot be identified by DAE. ${ }^{1,4}$

\section{INFLAMMATORY SMALL BOWEL DISEASE}

Patients with inflammatory or ulcerative disease generally present with abdominal pain or OGIB. Up to $66 \%$ of all patients with Crohn's disease have small bowel involvement at diagnosis; moreover, the terminal ileum is involved in approximately $90 \%$ of all patients with small bowel Crohn's disease. ${ }^{22,23}$ Patients with nonsteroidal anti-inflammatory drug-induced enteropathy can generally be evaluated by upper endoscopy; however, if the lesions are located in the small bowel, diagnostic approaches are difficult and VCE, DAE, or CT/MR enterography are required.
VCE is a useful diagnostic modality for Crohn's disease in patients with suspected inflammatory bowel disease or intermediate colitis. ${ }^{24} \mathrm{~A}$ recent meta-analysis reported a pooled detection rate of $55.3 \%$ in patients with suspected Crohn's disease. ${ }^{9}$ In a retrospective review of VCE performed in patients with Crohn's disease, 52 of 134 patients had findings diagnostic of active Crohn's disease ( $>3$ ulcerations), 17 patients had findings suggestive of active Crohn's disease ( $\leq 3$ ulcerations), and findings were normal in the remaining 57 patients $(42 \%)^{25}$ When VCE findings are normal, unnecessary examination of the small bowel can be avoided. In the same retrospective review, the distribution of small bowel lesions was as follows: $32 \%$ in the duodenum, $53 \%$ in the jejunum, $67 \%$ in the proximal ileum, and $85 \%$ in the distal ileum. VCE was found to be comparable to ileoscopy for the detection of ileal ulcerations ( $55 \%$ vs. $48 \%$ ), but superior to small bowel follow-through for the detection of Crohn's disease lesions. ${ }^{25}$

Although VCE has been shown to have high sensitivity (96\% to $100 \%$ ), VCE should be avoided in patients with suspected Crohn's disease in conjunction with stenosis or obstruction, as these patients may have a higher potential for capsule retention. ${ }^{26}$ If patients with suspected Crohn's disease present with obstructive symptoms or suspected stenosis, CT/MR enterography should be considered as the method of choice. ${ }^{1}$ Patency capsules can also be helpful in patients with suspected Crohn's disease in conjunction with obstruction or stenosis. ${ }^{27}$

In summary, the first-line approach in patients with suspected small bowel inflammatory disease is evaluation of the terminal ileum, including investigation and biopsy by colonoscopy. If it is not possible to evaluate the terminal ileum by colonoscopy, the small bowel should be assessed. VCE is a useful method for evaluating the small bowel; however, it is important to examine the small bowel for obstruction or

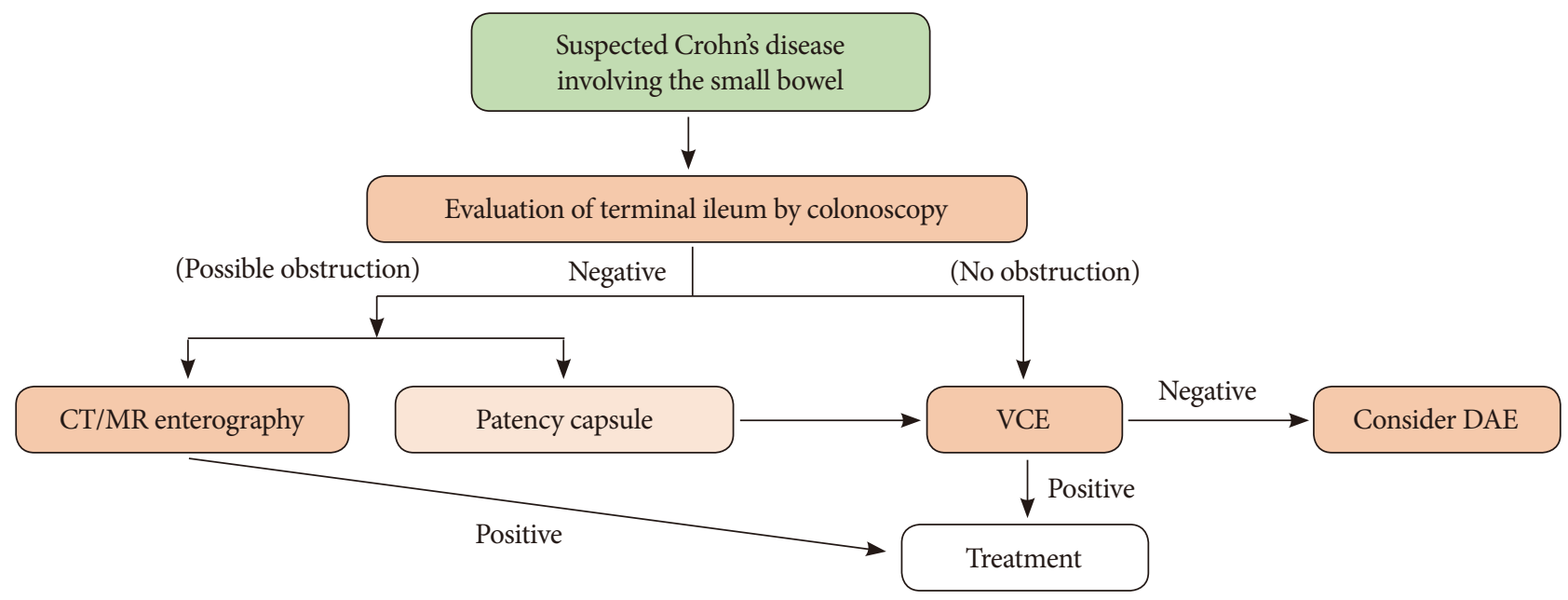

Fig. 2. Approach algorithm for a patient with Crohn's disease involving the small bowel. CT, computed tomography; MR, magnetic resonance; VCE, video capsule endoscopy; DAE, device-assisted enteroscopy. 
stenosis prior to performing VCE. When clinically suspected obstructions are present, the use of CT/MR enterography or patency capsules should be considered. Additionally, histologic evaluation can be performed using DAE, based on VCE or CT/MR enterography findings (Fig. 2). ${ }^{28,29}$

\section{SMALL BOWEL TUMORS}

Both malignant (such as adenocarcinoma, carcinoid tumors, lymphoma, and sarcoma) and benign (such as adenoma, leiomyoma, fibroma, and lipoma) tumors can occur in the small bowel. Most small bowel tumors are detected during work-up for OGIB or iron deficiency; however, tumors are the cause of these diseases in just $3.5 \%$ to $5 \%$ of patients. ${ }^{30}$ The clinical symptoms of small bowel tumors are generally nonspecific, which can delay diagnosis and optimal treatment. Although many advances in radiologic and endoscopic diagnostic tools have been made, an optimal method for detecting small bowel tumors has not yet been established. VCE and CT enterography are considered the most appropriate tools for detecting small bowel tumors in their early stages, whereas DAE is considered most appropriate for detecting small bowel tumors responsible for OGIB and those that are not identified by VCE. ${ }^{31,32}$

Upper gastrointestinal or small bowel series are not recommended as a first-line approach considering the low sensitivity of these methods for the detection of small bowel tumors. ${ }^{33}$ Large-scale meta-analyses have concluded that VCE is superior to small bowel series, push enteroscopy, and abdominal CT for detecting small bowel tumors in patients with gastrointestinal bleeding. ${ }^{34,35}$ Moreover, a recent retrospective study found that CT enterography was superior to VCE for the detection of small bowel tumors $(94.1 \%$ vs. $35.3 \%){ }^{28} \mathrm{VCE}$ itself does have some limitations, including the potential for misdiagnosis of transient intraluminal protrusions of the small bowel wall as submucosal tumors. ${ }^{34}$ The risk of false negative findings in VCE should always be considered. ${ }^{36}$ When small bowel adenocarcinoma is suspected, DAE or intraoperative enteroscopy may be required. VCE is unable to differentiate between benign and malignant lesions, especially in patients with inherited polyposis syndrome who have periampullary polyps. $^{34}$

When a small bowel tumor is detected using VCE, choice of treatment is generally based on the malignancy potential of the tumor. CT/MR enterography approaches are helpful for evaluating the extent of distant metastasis. When the potential for malignancy is high, DAE or surgery should be performed to diagnose and treat the tumor. If the findings of CT/MR enterography are normal, repeated VCE is recommended (Fig. 3). ${ }^{28,29}$

\section{SMALL BOWEL OBSTRUCTION}

Small bowel obstruction is a common clinical condition, the effective treatment of which is dependent on an accurate and prompt diagnosis. ${ }^{37}$ Conventional CT is considered the best modality for high-grade small bowel obstruction. This technique is also helpful for determining which patients would benefit most from conservative treatment and close observation or an immediate surgical treatment approach. ${ }^{38}$ However, conventional CT is less accurate in cases of lowgrade small bowel obstruction, with a sensitivity and specificity of $50 \%$ and $95 \%$, respectively. In comparison, CT enteroclysis with positive enteral contrast material has a superior performance, with a sensitivity and specificity of $89 \%$ and $100 \%$, respectively. ${ }^{39}$

\section{CONCLUSIONS}

Recent advances in VCE, DAE, and CT/MR enterography have facilitated a systematic approach toward evaluating small

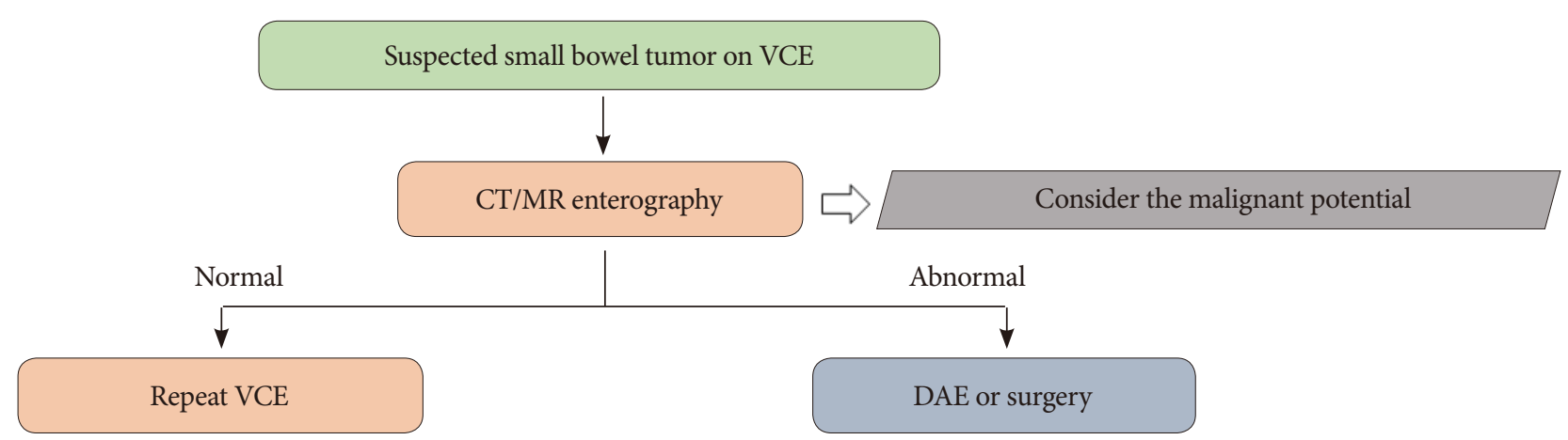

Fig. 3. Approach algorithm for a patient with a suspected small bowel tumor detected by capsule endoscopy. VCE, video capsule endoscopy; CT, computed tomography; MR, magnetic resonance; DAE, device-assisted enteroscopy. 
Table 1. Comparison of Small Bowel Imaging Modalities

\begin{tabular}{|c|c|c|c|}
\hline & Indications & Strengths & Weaknesses \\
\hline Video capsule endoscopy & $\begin{array}{l}\text { Obscure GI bleeding } \\
\text { Inflammatory small bowel disease } \\
\text { Small bowel tumors }\end{array}$ & $\begin{array}{l}\text { Direct visualization of entire } \\
\text { small bowel } \\
\text { High yield for mucosal lesions } \\
\text { Less invasive procedure }\end{array}$ & $\begin{array}{l}\text { Miss rate for isolated lesions } \\
\text { Risk of capsule retention with } \\
\text { obstructive disease } \\
\text { Difficult to distinguish cause of } \\
\text { inflammatory lesions }\end{array}$ \\
\hline Device-assisted enteroscopy & $\begin{array}{l}\text { Obscure GI bleeding } \\
\text { Inflammatory small bowel disease } \\
\text { Small bowel tumors }\end{array}$ & $\begin{array}{l}\text { Provides definitive histopathology } \\
\text { Therapeutic capabilities }\end{array}$ & $\begin{array}{l}\text { Requires deeper sedation } \\
\text { Invasive procedure } \\
\text { Time and staff intensive }\end{array}$ \\
\hline CT enterography & $\begin{array}{l}\text { Obscure GI bleeding } \\
\text { Inflammatory small bowel disease } \\
\text { Small bowel tumors }\end{array}$ & $\begin{array}{l}\text { Acquires entire small bowel } \\
\text { image } \\
\text { Noninvasive } \\
\text { Provides extraluminal } \\
\text { information }\end{array}$ & $\begin{array}{l}\text { Limited utility for flat lesions } \\
\text { Radiation exposure } \\
\text { Large amount of contrast } \\
\text { Allergy/renal disease }\end{array}$ \\
\hline MR enterography & $\begin{array}{l}\text { Obscure GI bleeding } \\
\text { Inflammatory small bowel disease } \\
\text { Small bowel tumors }\end{array}$ & $\begin{array}{l}\text { Acquires entire small bowel } \\
\text { image } \\
\text { Noninvasive } \\
\text { Provides extraluminal } \\
\text { information } \\
\text { No exposure of radiation }\end{array}$ & $\begin{array}{l}\text { Limited utility for flat lesions } \\
\text { Large amount of contrast } \\
\text { Time and staff intensive }\end{array}$ \\
\hline GI bleeding scan & Obscure GI bleeding & $\begin{array}{l}\text { Noninvasive } \\
\text { Good sensitivity for bleeding } \\
\text { rates of } 0.1-0.4 \mathrm{~cm}^{3} \text { blood } / \mathrm{min} \\
\text { Helpful for timing angiography }\end{array}$ & $\begin{array}{l}\text { Limited resolution } \\
\text { Imprecise for bleeding site } \\
\text { localization } \\
\text { Time and staff intensive }\end{array}$ \\
\hline Angiography & Obscure GI bleeding & $\begin{array}{l}\text { Rapid and noninvasive } \\
\text { Sensitive for bleeding rates of } \\
0.5-1.0 \mathrm{~cm}^{3} \text { blood } / \mathrm{min} \\
\text { Allows for therapeutic } \\
\text { embolization if feasible }\end{array}$ & $\begin{array}{l}\text { Less sensitive if performed during } \\
\text { period of inactive bleeding } \\
\text { Requires additional radiation and } \\
\text { contrast exposure }\end{array}$ \\
\hline
\end{tabular}

GI, gastrointestinal; CT, computed tomography; MR, magnetic resonance.

bowel disease. Both diagnostic and therapeutic approaches are necessary when taking the particular limitations and capabilities of each into consideration (Table 1). In summary, VCE is recommended in patients without symptoms of obstruction or stenosis, whereas CT/MR enterography or DAE is recommended for patients with suspected small bowel tumors or obstruction. Future studies and new diagnostic tools promise to pave the way for even more accurate and sensitive diagnostic approaches.

\section{Conflicts of Interest}

The authors have no financial conflicts of interest.

\section{REFERENCES}

1. Pennazio M, Spada C, Eliakim R, et al. Small-bowel capsule endoscopy and device-assisted enteroscopy for diagnosis and treatment of small-bowel disorders: European Society of Gastrointestinal Endoscopy (ESGE) Clinical Guideline. Endoscopy 2015;47:352-376

2. Lin S, Rockey DC. Obscure gastrointestinal bleeding. Gastroenterol Clin North Am 2005;34:679-698.
3. Leighton JA, Goldstein J, Hirota W, et al. Obscure gastrointestinal bleeding. Gastrointest Endosc 2003;58:650-655

4. Gerson LB, Fidler JL, Cave DR, Leighton JA. ACG clinical guideline: diagnosis and management of small bowel bleeding. Am J Gastroenterol 2015;110:1265-1287.

5. Raju GS, Gerson L, Das A, Lewis B; American Gastroenterological Association. American Gastroenterological Association (AGA) Institute technical review on obscure gastrointestinal bleeding. Gastroenterology 2007;133:1697-1717.

6. Descamps C, Schmit A, Van Gossum A. "Missed" upper gastrointestinal tract lesions may explain "occult" bleeding. Endoscopy 1999;31:452-455.

7. Liu K, Kaffes AJ. Review article: the diagnosis and investigation of obscure gastrointestinal bleeding. Aliment Pharmacol Ther 2011;34:416423.

8. Lim YJ, Lee OY, Jeen YT, et al. Indications for detection, completion, and retention rates of small bowel capsule endoscopy based on the 10year data from the Korean Capsule Endoscopy Registry. Clin Endosc 2015;48:399-404

9. Liao Z, Gao R, Xu C, Li ZS. Indications and detection, completion, and retention rates of small-bowel capsule endoscopy: a systematic review. Gastrointest Endosc 2010;71:280-286.

10. Pennazio M, Santucci R, Rondonotti E, et al. Outcome of patients with obscure gastrointestinal bleeding after capsule endoscopy: report of 100 consecutive cases. Gastroenterology 2004;126:643-653.

11. Ben Soussan E, Antonietti M, Hervé S, et al. Diagnostic yield and therapeutic implications of capsule endoscopy in obscure gastrointestinal 
bleeding. Gastroenterol Clin Biol 2004;28:1068-1073.

12. Estévez E, González-Conde B, Vázquez-Iglesias JL, et al. Diagnostic yield and clinical outcomes after capsule endoscopy in 100 consecutive patients with obscure gastrointestinal bleeding. Eur J Gastroenterol Hepatol 2006;18:881-888

13. Pasha SF, Leighton JA, Das A, et al. Double-balloon enteroscopy and capsule endoscopy have comparable diagnostic yield in small-bowel disease: a meta-analysis. Clin Gastroenterol Hepatol 2008;6:671-676.

14. Wang Z, Chen JQ, Liu JL, Qin XG, Huang Y. CT enterography in obscure gastrointestinal bleeding: a systematic review and meta-analysis. J Med Imaging Radiat Oncol 2013;57:263-273.

15. Li XB, Ge ZZ, Dai J, et al. The role of capsule endoscopy combined with double-balloon enteroscopy in diagnosis of small bowel diseases. Chin Med J (Engl) 2007;120:30-35.

16. Yen HH, Chen YY, Yang CW, Liu CK, Soon MS. Clinical impact of multidetector computed tomography before double-balloon enteroscopy for obscure gastrointestinal bleeding. World J Gastroenterol 2012;18:692697.

17. Heiss P, Zorger N, Hamer OW, et al. Optimized multidetector computed tomographic protocol for the diagnosis of active obscure gastrointestinal bleeding: a feasibility study. J Comput Assist Tomogr 2009;33:698704 .

18. Ettorre GC, Francioso G, Garribba AP, Fracella MR, Greco A, Farchi G. Helical CT angiography in gastrointestinal bleeding of obscure origin. AJR Am J Roentgenol 1997;168:727-731.

19. Saperas E, Dot J, Videla S, et al. Capsule endoscopy versus computed tomographic or standard angiography for the diagnosis of obscure gastrointestinal bleeding. Am J Gastroenterol 2007;102:731-737.

20. Brunnler T, Klebl F, Mundorff S, et al. Significance of scintigraphy for the localisation of obscure gastrointestinal bleedings. World J Gastroenterol 2008;14:5015-5019.

21. May A, Färber M, Aschmoneit I, et al. Prospective multicenter trial comparing push-and-pull enteroscopy with the single- and double-balloon techniques in patients with small-bowel disorders. Am J Gastroenterol 2010;105:575-581.

22. Van Assche G, Dignass A, Panes J, et al. The second European evidence-based consensus on the diagnosis and management of Crohn's disease: definitions and diagnosis. J Crohns Colitis 2010;4:7-27.

23. Jensen MD, Nathan T, Rafaelsen SR, Kjeldsen J. Ileoscopy reduces the need for small bowel imaging in suspected Crohn's disease. Dan Med J 2012;59:A4491.

24. Mishkin DS, Chuttani R, Croffie J, et al. ASGE technology status evaluation report: wireless capsule endoscopy. Gastrointest Endosc 2006;63:539-545

25. Mehdizadeh S, Chen GC, Barkodar L, et al. Capsule endoscopy in patients with Crohn's disease: diagnostic yield and safety. Gastrointest Endosc 2010;71:121-127.
26. Kopylov U, Seidman EG. Role of capsule endoscopy in inflammatory bowel disease. World J Gastroenterol 2014;20:1155-1164.

27. Yadav A, Heigh RI, Hara AK, et al. Performance of the patency capsule compared with nonenteroclysis radiologic examinations in patients with known or suspected intestinal strictures. Gastrointest Endosc 2011;74:834-839.

28. Hakim FA, Alexander JA, Huprich JE, Grover M, Enders FT. CT-enterography may identify small bowel tumors not detected by capsule endoscopy: eight years experience at Mayo Clinic Rochester. Dig Dis Sci 2011;56:2914-2919.

29. Dye CE, Gaffney RR, Dykes TM, Moyer MT. Endoscopic and radiographic evaluation of the small bowel in 2012. Am J Med 2012;125:1228. e1-1228.e12.

30. Koulaouzidis A, Rondonotti E, Giannakou A, Plevris JN. Diagnostic yield of small-bowel capsule endoscopy in patients with iron-deficiency anemia: a systematic review. Gastrointest Endosc 2012;76:983-992.

31. Huprich JE, Fletcher JG, Alexander JA, Fidler JL, Burton SS, McCullough $\mathrm{CH}$. Obscure gastrointestinal bleeding: evaluation with 64-section multiphase CT enterography: initial experience. Radiology 2008;246:562-571.

32. Ross A, Mehdizadeh S, Tokar J, et al. Double balloon enteroscopy detects small bowel mass lesions missed by capsule endoscopy. Dig Dis Sci 2008;53:2140-2143.

33. Mergener K, Ponchon T, Gralnek I, et al. Literature review and recommendations for clinical application of small-bowel capsule endoscopy, based on a panel discussion by international experts. Consensus statements for small-bowel capsule endoscopy, 2006/2007. Endoscopy 2007;39:895-909.

34. Triester SL, Leighton JA, Leontiadis GI, et al. A meta-analysis of the yield of capsule endoscopy compared to other diagnostic modalities in patients with non-stricturing small bowel Crohn's disease. Am J Gastroenterol 2006;101:954-964.

35. Triester SL, Leighton JA, Leontiadis GI, et al. A meta-analysis of the yield of capsule endoscopy compared to other diagnostic modalities in patients with obscure gastrointestinal bleeding. Am J Gastroenterol 2005;100:2407-2418.

36. Postgate A, Despott E, Burling D, et al. Significant small-bowel lesions detected by alternative diagnostic modalities after negative capsule endoscopy. Gastrointest Endosc 2008;68:1209-1214.

37. Maglinte DD, Howard TJ, Lillemoe KD, Sandrasegaran K, Rex DK. Small-bowel obstruction: state-of-the-art imaging and its role in clinical management. Clin Gastroenterol Hepatol 2008;6:130-139.

38. Maglinte DD, Heitkamp DE, Howard TJ, Kelvin FM, Lappas JC. Current concepts in imaging of small bowel obstruction. Radiol Clin North Am 2003;41:263-283.

39. Maglinte DD, Sandrasegaran K, Lappas JC, Chiorean M. CT Enteroclysis. Radiology 2007;245:661-671. 